\title{
LEITURA E MULTIMODALIDADE: REFLEXÕES EM TORNO DO TEXTO ACADÊMICO'1
}

\author{
TALITA SANTOS MENEZES (UFS) ${ }^{2}$ \\ https://orcid.org/0000-0002-5985-062x
}

\begin{abstract}
RESUMO: Este trabalho tem como objetivo verificar se há variação na compreensão de textos acadêmicos que integram mais ou menos recursos multimodais. Tendo em vista que recursos gráficos, espaciais e ilustrativos, agregados a informações verbais, tornam o texto acadêmico um produto multimodal, torna-se válido investigar a influência de tais recursos na leitura de estudantes universitários que lidam com esse tipo de texto. O estudo assume um caráter descritivo, bem como uma abordagem quantiqualitativa, sendo classificado como bibliográfico e de campo. O referencial teórico é pautado, fundamentalmente, em pressupostos defendidos por Elias e Silva (2018), Kleiman (2016), Luz (2010), Mayer (2005), Padilla (2018), entre outros. Além disso, o trabalho traz resultados de um estudo de campo de caráter exploratório. Tal estudo consistiu em um pré-teste realizado com graduandos da Universidade Federal de Sergipe (UFS). A pesquisa demonstrou que recursos multimodais como ilustrações, por exemplo, podem gerar três tipos de efeito sobre a leitura de um texto acadêmico, isto é, elas podem auxiliar na melhor compreensão do conteúdo e localização de informações específicas; podem apenas acompanhar a informação verbal, de sorte que esta pode ser preponderante para o entendimento de um assunto; e, de certa forma, podem gerar algum tipo de dificuldade para o leitor integrar a informação verbal à visual, e, consequentemente, interpretar um dado.
\end{abstract}

PALAVRAS-CHAVE: Leitura. Recursos multimodais. Ilustrações. Texto acadêmico.

ABSTRACT: This work aims to verify if there is variation in the comprehension of texts academics that integrate more or less multimodal resources. Considering that resources graphics, spatial and illustrative, added to verbal information make the academic text multimodal product, it becomes valid to investigate the influence of such resources on reading university students dealing with this type of text. The study takes on a descriptive as well as a quantitative and qualitative approach being classified as bibliographic and field search. The theoretical framework is based, fundamentally, on assumptions defended by Elias e Silva (2018), Kleiman (2016), Luz (2010), Mayer (2005), Padilla (2018) among others. In addition, the work brings results of an exploratory field study. The study consisted of a pre-test conducted with undergraduate students from the Universidade Federal de Sergipe (UFS). Research has shown that multimodal resources such as illustrations for example can have three types of effect on the reading of an academic text, in other words, they can produce a better understanding of the content and location of specific information; they can only follow verbal information, so it can be preponderant for understanding a subject; and, in a way, they can generate some kind of difficulty for the reader to integrate verbal and visual information and consequently to interpret the data.

KEYWORDS: Reading. Multimodal resources. Illustrations. Academic text.

\section{INTRODUÇÃO}

Nas investigações realizadas em torno da leitura e da escrita de textos, estudiosos têm considerado, cada vez mais, a coexistência de duas ou mais modalidades de linguagem na

\footnotetext{
1 Este artigo traz resultados parciais de uma pesquisa em andamento. Vale ressaltar que a pesquisa foi submetida e aprovada pelo Comitê de Ética em Pesquisa da Universidade Federal de Sergipe (CEP/UFS), sob CAAE: 21002619.1.0000.5546, e todos os sujeitos envolvidos assinaram o Termo de Consentimento Livre e Esclarecido (TCLE).

2 Doutoranda em Letras pela Universidade Federal de Sergipe. E-mail: menezestalita@hotmail.com Revista Trama | Volume 16 | Número 39 | Ano 2020 | pp. 54-64 | e-ISSN 1981-4674
} 


\section{$=$ TRAMA $=$}

composição dos textos que circulam pela mídia impressa e digital. Tem-se observado que diferentes modos semióticos - tais como palavras, imagens, sons, cores, linhas, tipografia, animações, entre outros recursos carregados de significado - são combinados para gerar sentidos nos chamados textos multimodais.

Essa integração entre a linguagem verbal e a não verbal também é uma característica de textos que circulam pelo ambiente acadêmico. Nessa perspectiva, resumos, resenhas, fichamentos, relatórios, artigos, entre outros gêneros típicos do meio científico trazem em sua composição, além de informações verbais, diversos recursos gráficos (fonte, tamanho, estilo, cor e sinais tipográficos), espaciais (recuo, entrelinha e posição na página) e ilustrativos (quadro, figura, gráfico, tabela, mapa etc.). Todavia, esses recursos nem sempre recebem a devida atenção "[...] quando trabalhados apenas do ponto de vista da formatação, para atender às normas do discurso acadêmico. [...] esses elementos, vistos sob o prisma de normas a serem seguidas, ganham a antipatia e o desinteresse dos alunos." (ELIAS; SILVA, 2018, p. 122).

Nesse contexto, considerando que a formação acadêmica engloba uma série de habilidades relacionadas à leitura e à escrita de textos acadêmicos, e o sucesso na aprendizagem do graduando depende dessas habilidades, torna-se válido investigar os impactos que recursos multimodais podem causar na compreensão leitora desse estudante. Diante disso, a questão levantada neste estudo é: recursos multimodais interferem na compreensão de textos acadêmicos?

O objetivo deste trabalho é, então, verificar se há variação na compreensão de textos acadêmicos que integram mais ou menos recursos multimodais. Para isto, torna-se fundamental identificar recursos multimodais utilizados em textos acadêmicos, descrever a função desses recursos no processo de leitura, bem como avaliar a compreensão leitora de estudantes universitários a partir de textos acadêmicos que agregam mais ou menos recursos multimodais.

Esta investigação tem um caráter descritivo e possui uma abordagem quantiqualitativa, sendo classificada como bibliográfica e de campo. O referencial teórico é pautado, fundamentalmente, em pressupostos defendidos por Elias e Silva (2018), Kleiman (2016), Luz (2010), Mayer (2005), Padilla (2018), entre outros. Além disso, o trabalho traz resultados de um estudo de campo de caráter exploratório. Tal estudo consistiu em um pré-teste realizado com graduandos da Universidade Federal de Sergipe (UFS). A ação envolveu a leitura de um artigo científico impresso, contendo diferentes elementos multimodais, e uma versão editada desse artigo - sem esses elementos, bem como o preenchimento de um questionário de sondagem, composto de perguntas abertas e fechadas relacionadas (entre outras questões) à compreensão textual dos participantes.

O trabalho, inicialmente, traz uma breve discussão teórica acerca da concepção de leitura adotada no estudo, como também sobre aspectos do texto acadêmico - com ênfase nos recursos multimodais. Em seguida, descreve os percursos metodológicos adotados na investigação, assim como apresenta e discute os dados. Por fim, expõe os principais resultados obtidos com a pesquisa.

\section{FUNDAMENTAÇÃO TEÓRICA}

A atividade de leitura pode ser entendida como um processo de compreensão textual que envolve a produção de sentidos. Tal processo é marcado por aspectos de ordem cognitiva, interacional, textual, linguística, social etc., e se estabelece na relação entre o autor, o texto e o leitor (KLEIMAN, 2016). Assim, no corpo do texto, "a materialização de uma intenção do autor se dá através de elementos tanto linguísticos como gráficos, cabendo ao leitor a recuperação dessa intenção através do formal." (KLEIMAN, 2016, p. 49). Dessa forma, o leitor considera o que foi exposto pelo autor, mas não é apenas isso; ele assume uma postura ativa na construção 


\section{$=$ TRAMA $=$}

dos sentidos do texto, ao levantar hipóteses, fazer inferências, criticar ideias, aceitar ou rejeitar conclusões. Por outro lado, o autor objetiva "a adesão do leitor, apresentando para isso, da melhor maneira possível, os melhores argumentos, a evidência mais convincente da forma mais clara possível, organizando e deixando no texto pistas formais a fim de facilitar a consecução do seu objetivo." (KLEIMAN, 2016, p. 71).

Nesse contexto, o elemento textual também terá significativa relevância para o processo de compreensão. Aspectos como linguagem, gênero ou estrutura, por exemplo, fazem toda diferença na construção dos sentidos de um texto.

No caso dos textos que circulam pelo ambiente acadêmico, há especificidades que os diferenciam daqueles lidos e/ou produzidos em outros ambientes. Sobre isso, Padilla (2018) esclarece que a comunicação que se estabelece na comunidade acadêmica e disciplinar é convencionalizada por meio de gêneros textuais científicos, os quais têm modos de organização específicos. Assim, a partir de experiências de leitura e escrita adquiridas ao longo do curso, o graduando passa a reconhecer os diversos tipos de fichamento, os modos de organização de um seminário, as partes que compõem um artigo ou mesmo a diferença entre um resumo e uma resenha, por exemplo.

O texto acadêmico pode ser visto como "produto de um processo de argumentação científica que é legitimado nos diferentes âmbitos disciplinares." (PADILLA, 2018, p. 273). Esse tipo de argumentação busca o assentimento mediante o apelo ao racional. Por isso, o autor de um texto acadêmico não se apoia em apelos emocionais, mas em dados concretos, fatos e informações verificáveis.

Outra característica do texto acadêmico é a integração entre diferentes modos de linguagem, de sorte que a junção da linguagem verbal com a não verbal o torna um produto multimodal.

Mayer (2005) define multimídia (ou multimodal) o material que associa palavras e elementos pictóricos, de sorte que as palavras representam o aspecto verbal (texto falado ou impresso) e os recursos pictóricos incluem gráficos, ilustrações, diagramas, fotos, entre outros. A partir dos princípios da Teoria Cognitiva da Aprendizagem Multimídia (TCAM), o autor assegura que estudantes aprendem mais com palavras e imagens do que apenas com palavras. Dessa forma, a aprendizagem multimídia ocorre quando o indivíduo é capaz de construir representações mentais de aspectos verbais e não verbais presentes em textos impressos ou digitais. Mayer (2005) defende esse princípio argumentando que os seres humanos têm dois sistemas de processamento de informações: um para o material verbal e outro para o material visual. Logo, uma aprendizagem realmente significativa é aquela que envolve ambos os sistemas.

Há de se considerar que, atualmente, a literatura que trata da multimodalidade - em termos de uso e funcionalidade das diferentes formas de representação que compõem os textos, bem como os processos de produção e compreensão de materiais multimodais - é relativamente significativa, abarcando, inclusive, a análise de textos da área acadêmicocientífica (ARAÚJO; PIMENTA, 2014; BEZERRA, 2010; FERREIRA, 2017; FLOREK, 2016; KOMESU, 2012; MORAES, 2007).

Nesse contexto, o artigo científico, considerado "o gênero textual mais conceituado na divulgação do saber especializado acadêmico" (MOTTA-ROTH; HENDGES, 2010, p. 66), é um exemplo de texto acadêmico multimodal. Embora a análise da integração de arranjos multissemióticos em sua materialidade textual ainda não seja muito vasta na literatura, possivelmente por se tratar de "uma produção baseada em normas e limitações que são impostas por determinadas comunidades científicas/editoriais a fim de que sejam produzidos textos que se baseiam em modelos impressos, isto é, com as limitações próprias do suporte em 


\section{$=$ TRAMA $=$}

questão" (FERREIRA, 2017, p. 79), pode-se dizer que recursos gráficos (fonte, tamanho, estilo, cor e sinais tipográficos), espaciais (recuo, entrelinha e posição na página) e, principalmente, ilustrativos (quadro, figura, gráfico, tabela, mapa etc.), utilizados na composição desse gênero, são elementos multimodais. Segundo Elias e Silva (2018, p. 115), esses recursos funcionam como "importantes sinalizadores do modo de organização do texto, dos tópicos que o compõem e das partes que merecem destaque no processo argumentativo e que foram configuradas de determinado modo para orientar a leitura e a compreensão".

Esses recursos podem desempenhar diferentes funções na composição do artigo científico. Conforme Elias e Silva (2018), as fontes - disponíveis em uma ampla variedade podem ser usadas em diferentes cores para marcar títulos, subtítulos, como também o nome dos autores nos artigos. A ênfase dada à determinada expressão pode ser feita pelo recurso itálico ou negrito, por outra cor ou ainda por uma fonte ou tamanho diferente do texto. Ademais, alguns recursos espaciais ou gráficos também podem ser usados na hierarquização tipográfica, a qual organiza o conteúdo e orienta o leitor ao longo do texto.

Nessa mesma perspectiva, Luz (2010, p. 29) afirma que a tabela "resume dados numéricos sobre uma ou mais variáveis, dispostos em forma de colunas e linhas para fins de apresentação ou comparação". Na visão do autor, as tabelas desempenham um importante papel na comunicação de dados estatísticos tanto por seu caráter descritivo quanto por facilitar a visualização dos dados. Convém ressaltar que, segundo as normas de apresentação tabular (IBGE, 1993), em uma tabela, o dado numérico é a informação central. Já no que tange ao quadro, não há um consenso na literatura sobre o tipo de conteúdo que deve expor, o que permite seu uso tanto para dados numéricos quanto para dados linguísticos.

O gráfico, por sua vez, "é a forma de apresentação das séries estatísticas através de representação gráfica, cuja finalidade é produzir no observador uma conclusão rápida e global sobre a evolução do fenômeno em estudo ou dos dados estatísticos pesquisados." (LUZ, 2010, p. 37). Seguindo esse viés, Lupton (2006, p. 130) afirma: "tabelas e gráficos permitem que as relações numéricas sejam rapidamente percebidas e comparadas. Neles, o diagrama é uma ferramenta cognitiva".

Ao entender a leitura como uma atividade de produção de sentidos, a qual reúne aspectos de ordem cognitiva, interacional, social etc., e que se dá na relação autor-texto-leitor, entende-se que, para a (re)construção dos sentidos de um texto acadêmico (como o artigo, por exemplo) que agrega recursos multimodais como os supracitados, o leitor precisa relacionar as informações obtidas através desses recursos àquelas apresentadas no texto verbal, e, de certa forma, identificar a função do recurso ali inserido.

\section{METODOLOGIA}

A primeira etapa deste estudo consistiu na seleção de artigos científicos para uso na coleta de dados. Dessa forma, seguindo as orientações de Sampaio e Mancini (2007), foi realizada uma revisão sistemática.

A estratégia de busca teve como foco artigos publicados em periódicos das bases Capes e Scielo. Como uma das questões inseridas na pesquisa diz respeito ao conhecimento prévio dos graduandos sobre o conceito de multimodalidade, optou-se pela busca por artigos que abordassem, especificamente, esse tema. Sendo assim, o descritor utilizado foi "multimodalidade" no título dos textos. Os critérios de inclusão elencados foram: a) ser a versão completa do trabalho; b) estar escrito em Língua Portuguesa. Os critérios de exclusão adotados foram: a) não atendimento aos critérios de inclusão; b) não se encaixar na categoria do gênero definido; c) ser um texto duplicado, ou seja, que aparece em mais de um resultado de busca. Diante disso, foram encontrados 59 artigos, dos quais 26 foram selecionados por atenderem 


\section{$=$ TRAMA $=$}

aos critérios definidos. Desse conjunto, um foi escolhido ${ }^{3}$ para ser utilizado na coleta dos dados. Essa escolha se deu mediante os seguintes critérios: a) apresentar tema relacionado a conteúdos estudados pelos participantes da pesquisa durante a graduação; b) conter dois ou mais tipos de elementos ilustrativos; c) ter uma quantidade máxima de dez laudas - para não ser uma leitura muito fatigante aos participantes da pesquisa.

O artigo selecionado passou por uma adaptação. Elementos não verbais como gráficos, tabelas e figuras foram retirados, e referências textuais atribuídas a esses elementos foram editadas. O foco nessa categoria de recursos multimodais justifica-se pelo entendimento de que as ilustrações não se limitam a aspectos da superfície textual, mas lidam com formas específicas de sumarização de informações em formatos visuais. Assim, as ilustrações acompanham a informação verbal, apresentando os dados de forma mais rápida e global para os leitores, o que pode influenciar o processo de compreensão.

Convém ressaltar, ainda, que tal adaptação foi feita de modo a preservar tanto a estrutura "padrão" (título, autor, resumo, palavras-chave, introdução, desenvolvimento, conclusão e referências) quanto o conteúdo do texto original. Desse modo, foram obtidas duas versões do artigo: Texto A (versão original, com ilustrações) e Texto B (versão adaptada, sem ilustrações).

Com base em ambas as versões do artigo, foram elaborados dois questionários de sondagem. Esses instrumentos foram compostos de perguntas abertas e fechadas, a partir das quais havia a pretensão de verificar (entre outros aspectos) a compreensão textual dos graduandos em cada versão do artigo ( $\mathrm{A}$ e B), comparar os dados e apurar se há variação entre a compreensão de um artigo que integra mais recursos pictográficos em sua composição daquele que apresenta menos arranjos de modos semióticos.

A etapa seguinte consistiu em uma ação com graduandos do curso de Letras Estrangeiras da Universidade Federal de Sergipe (UFS). Como foi utilizada a amostra por conveniência, ou seja, aquela em que o pesquisador seleciona os sujeitos "que se mostrem mais acessíveis, colaborativos ou disponíveis para participar do processo" (FREITAG, 2018, p. 671), da turma escolhida, dez ${ }^{4}$ estudantes foram voluntários na pesquisa.

A ação consistiu na divisão dos participantes em dois grupos e entrega das duas versões (uma para cada grupo) do artigo selecionado com seus respectivos questionários, a partir dos quais foram obtidos alguns dos resultados preliminares expostos e discutidos a seguir.

\section{ANÁLISE E DISCUSSÃO DOS RESULTADOS}

O Texto A, além de recursos gráficos e espaciais, trazia três tipos de ilustrações: figuras, tabelas e gráficos. Em contrapartida, o Texto B - a versão editada - não possuía esses recursos.

Das figuras presentes no Texto A (expostas no Quadro 1), duas estavam inseridas na seção do referencial teórico e uma foi usada na seção de resultados e discussões.

\footnotetext{
${ }^{3} \mathrm{O}$ artigo escolhido tem como título "Classificação de Objetos de Aprendizagem Segundo o Grau de Multimodalidade" (CANTO FILHO et al., 2013). Disponível em: https://bit.ly/3cCg4CE

${ }^{4}$ Por motivos de força maior, não foi possível aplicar o pré-teste a um grupo mais significativo de graduandos. Como o intuito do estudo, nessa fase, era a realização de uma testagem dos instrumentos de coleta de dados, a quantidade de material coletado, ainda que pequena, foi satisfatória. Todavia, salienta-se que, no decorrer da pesquisa, a amostra será ampliada.
}

Revista Trama | Volume 16 | Número 39 | Ano 2020 | pp. 54-64 | e-ISSN 1981-4674 


\section{$=$ TRAMA $=$}

Quadro 1 - Figuras presentes no Texto A

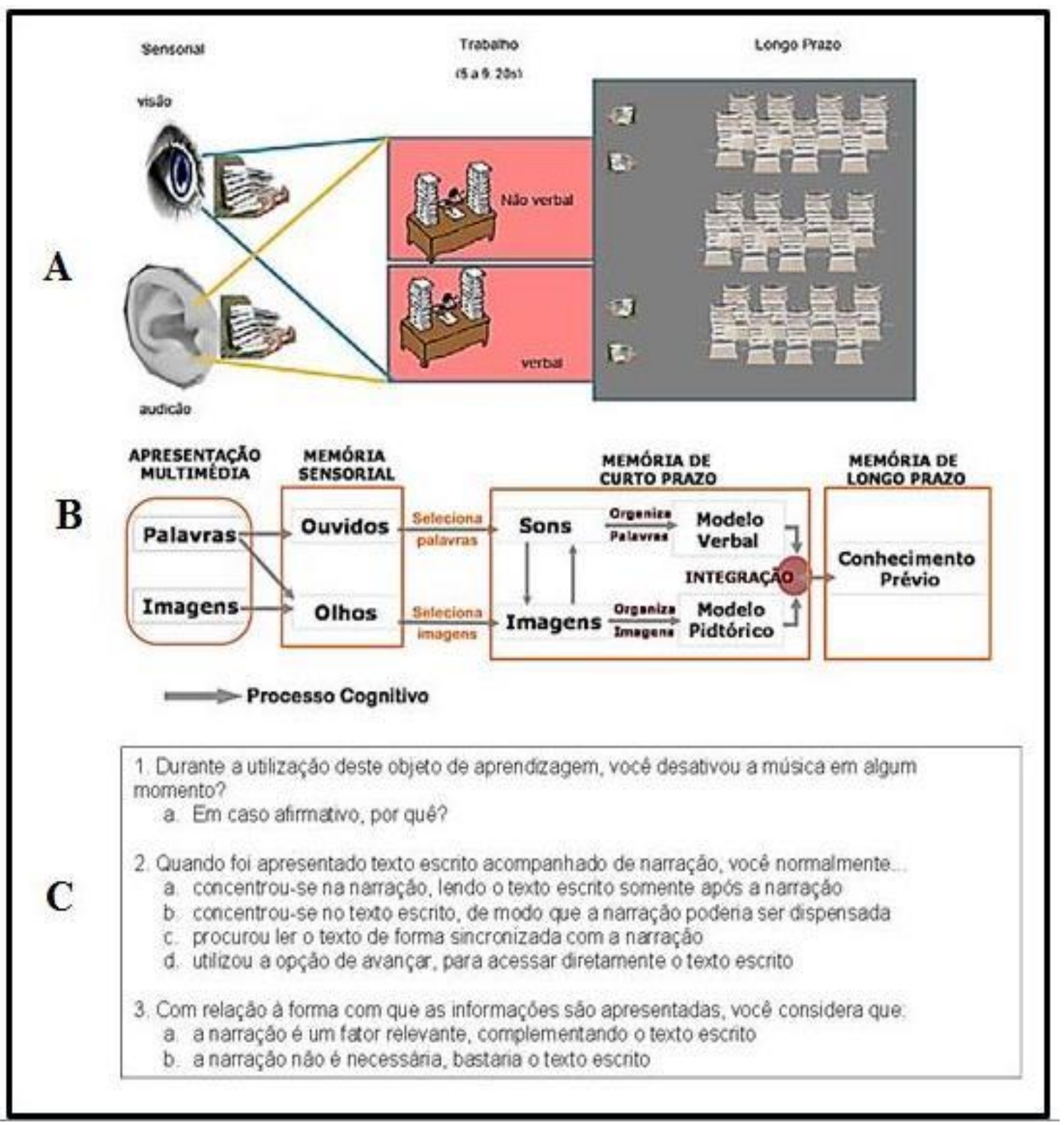

Fonte: elaboração própria com base no Texto A.

No texto, a Figura A dá suporte à exposição da Teoria da Carga Cognitiva. Ela é mencionada quando os autores discutem a respeito da arquitetura cognitiva humana e sua relação com os três tipos de memória - sensorial, trabalho e longo prazo. A Figura B, por sua vez, acompanha a explicação acerca do processamento de informações feito pelos seres humanos através de dois canais - verbal e visual. Já a Figura $C$ expõe as questões utilizadas pelos autores do artigo durante a coleta de dados da pesquisa.

O Texto A também traz duas tabelas ${ }^{5}$, as quais são expostas no Quadro 2:

\footnotetext{
${ }^{5}$ Apesar da discussão (não consensual) sobre a diferença entre quadros e tabelas, optou-se por seguir a nomenclatura utilizada pelos autores do artigo em análise.
}

Revista Trama | Volume 16 | Número 39 | Ano 2020 | pp. 54-64 | e-ISSN 1981-4674 


\section{$=$ TRAMA $=$}

Quadro 2 - Tabelas presentes no Texto A

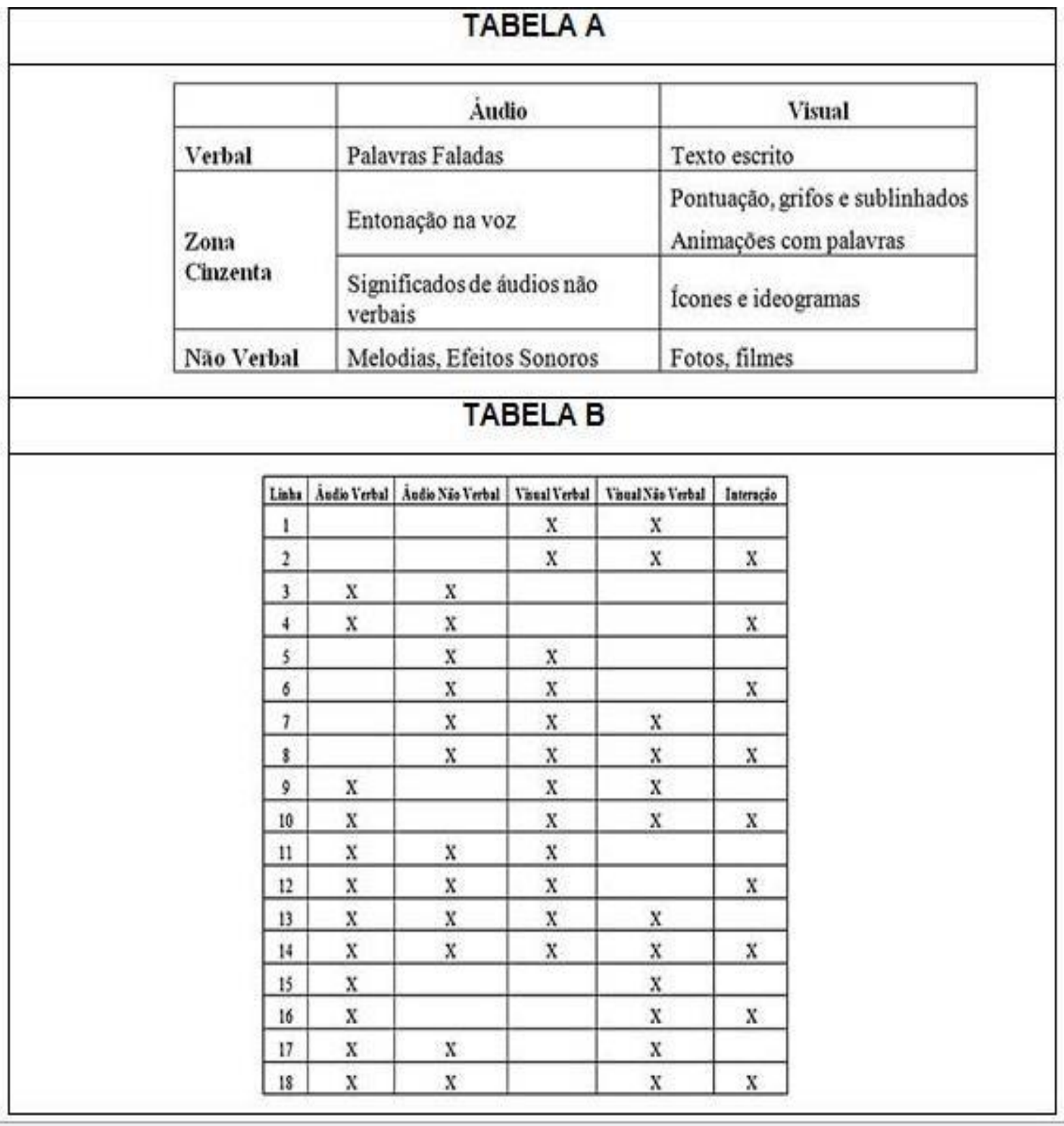

Fonte: elaboração própria com base no Texto A.

A Tabela A acompanha a explicação dos autores sobre a existência de uma "zona cinzenta" entre a informação verbal e a não verbal presente em objetos de aprendizagem. Essa ilustração traz exemplos para cada interconexão entre os modos de linguagem, o que pode deixar mais claro o conteúdo exposto na seção. Já a Tabela B mostra as categorias do sistema criado pelos autores para a classificação de objetos de aprendizagem quanto ao tipo de multimodalidade.

Ainda no Texto A constam três gráficos, os quais apresentam os resultados obtidos com o questionário que os autores aplicaram. O Quadro 3 apresenta tais ilustrações: 


\section{$=\mathrm{T} R A M A=$}

Quadro 3 - Gráficos presentes no Texto A

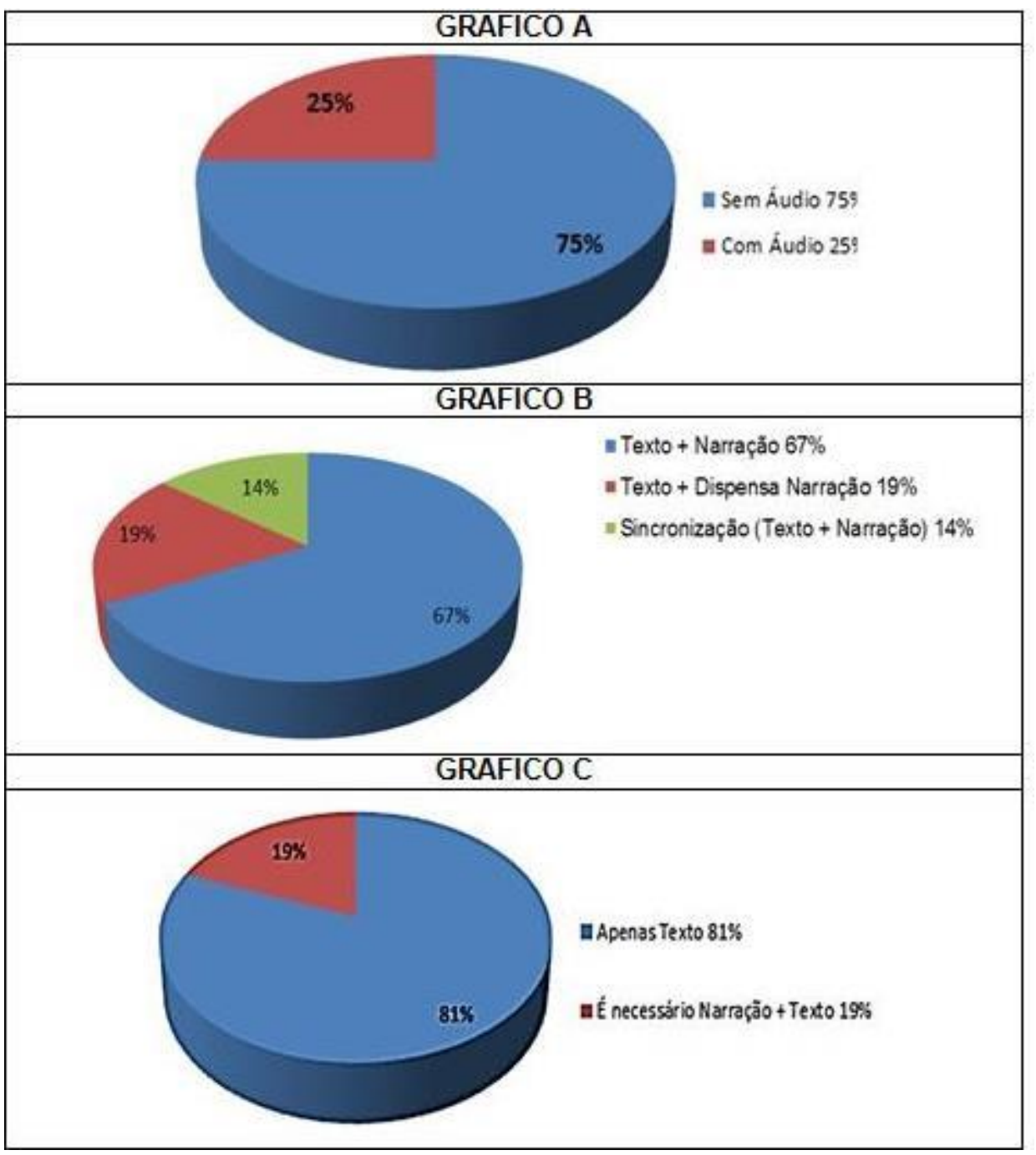

Fonte: elaboração própria com base no Texto A.

No experimento realizado pelos autores do trabalho, os participantes da pesquisa deveriam dizer como as mídias contidas no objeto de aprendizagem em teste influenciaram na sua capacidade de interação com software. Sendo assim, o Gráfico A apresenta as porcentagens de participantes que optaram (ou não) por desabilitar a música de fundo durante a execução do objeto de aprendizagem. O Gráfico B mostra os resultados sobre a reação dos participantes diante da apresentação do texto simultaneamente em dois formatos, áudio e escrito, disponíveis no software. O Gráfico C, por sua vez, traz os resultados da opinião dos participantes quanto à apresentação simultânea de narração e texto escrito.

Tendo isso em vista, para averiguar a compreensão textual dos participantes de cada grupo, foram elaboradas cinco questões de múltipla escolha e uma de "verdadeiro ou falso" sobre tópicos específicos do artigo. Dessa forma, os participantes de ambos os grupos tinham acesso às mesmas questões. A única diferença foi que os participantes que leram o Texto $A$, além da informação verbal, tinham as ilustrações como apoio para a compreensão do assunto. Já os estudantes que leram o Texto B contavam apenas com a exposição do conteúdo em formato verbal. 


\section{$=$ TRAMA $=$}

A tabela abaixo mostra os resultados obtidos nas questões de múltipla escolha em cada texto:

Tabela 1 - Questões de múltipla escolha

\begin{tabular}{|l|c|c|c|c|}
\cline { 2 - 5 } \multicolumn{1}{c|}{} & \multicolumn{2}{c|}{ TEXTO A } & \multicolumn{2}{c|}{ TEXTO B } \\
\cline { 2 - 5 } \multicolumn{1}{c|}{} & Acertos & Erros & Acertos & Erros \\
\hline Questão 1 & $100 \%$ & - & $60 \%$ & $40 \%$ \\
\hline Questão 2 & $100 \%$ & - & $100 \%$ & - \\
\hline Questão 3 & $100 \%$ & - & $80 \%$ & $20 \%$ \\
\hline Questão 4 & $80 \%$ & $20 \%$ & $80 \%$ & $20 \%$ \\
\hline Questão 5 & $80 \%$ & $20 \%$ & $80 \%$ & $20 \%$ \\
\hline
\end{tabular}

Fonte: elaboração própria.

A Questão 1 tinha como objetivo averiguar se o participante conseguia identificar o tema do texto. Observando a Tabela 1, verifica-se que todos os participantes que leram o Texto A acertaram a resposta. Por outro lado, $60 \%$ dos alunos que leram o Texto B acertaram e $40 \%$ erraram a resposta. Embora se trate de uma questão que exigia um entendimento mais global do texto, sem necessariamente se relacionar a aspectos específicos expostos por alguma ilustração, fica notória a melhor compreensão do tema por parte do grupo que leu o texto em que havia ilustrações.

Com as questões 2, 3, 4 e 5, tinha-se a intenção de observar se o participante sabia localizar informações explícitas no texto, integrando-as a aspectos não verbais - no caso do Texto A - ou fazendo inferências a partir delas - no caso do Texto $B$.

A Questão 2 solicitava ao participante a identificação dos três tipos de memória existentes na arquitetura cognitiva humana. A Tabela 1 mostra que os participantes de ambos os grupos acertaram a resposta. Isso pode sugerir que, nessa questão, a ilustração (Figura A) teria apenas a função de acompanhar o conteúdo verbal, uma vez que os leitores do Texto $B$ identificaram a informação sem necessitar do auxílio do recurso visual.

A terceira questão era voltada à constatação dos sentidos associados aos dois canais de processamento humano de informações. Os resultados dessa questão mostram uma pequena variação entre ambos os grupos. Assim, enquanto 100\% dos estudantes que leram o Texto A acertaram a resposta, o grupo que leu o Texto B apresentou $80 \%$ de acerto. Nesse caso, diferente do que ocorreu na questão anterior, a Figura A pode ter auxiliado (um pouco mais que o texto verbal) os graduandos na identificação da resposta correta.

A questão 4 trazia afirmativas sobre a "zona cinzenta" existente entre informações verbais e não verbais. Já a questão 5 solicitava que o participante apontasse as cinco categorias utilizadas no estudo para a classificação de objetos de aprendizagem quanto ao tipo de multimodalidade. Ambas as questões tiveram os mesmos resultados de acerto e erro nos dois grupos ( $80 \%$ e $20 \%$ respectivamente). Sendo assim, é possivel que as tabelas A e B relacionadas às questões 4 e 5 respectivamente - poderiam desenvolver apenas a função de acompanhar o conteúdo verbal, já que os estudantes que não tiveram acesso a essas ilustrações conseguiram extrair a informação do texto sem auxílio do recurso visual.

Outra questão que tratava da compreensão textual dos estudantes quanto ao assunto discutido no artigo foi a de "Verdadeiro ou Falso". Essa questão trazia afirmativas sobre o método utilizado pelos autores do artigo na pesquisa, bem como sobre os resultados obtidos com o experimento realizado por eles. A tabela abaixo traz os resultados dessa questão. 


\section{$=$ TRAMA $=$}

Tabela 2 - Questão "verdadeiro ou falso"

\begin{tabular}{|l|c|c|c|c|c|}
\cline { 2 - 6 } \multicolumn{1}{c|}{} & \multicolumn{3}{c|}{ TEXTO A } & \multicolumn{2}{c|}{ TEXTO B } \\
\cline { 2 - 6 } \multicolumn{1}{c|}{} & Acertos & Erros & Sem resposta & Acertos & Erros \\
\hline Sentença 1 & $60 \%$ & $20 \%$ & $20 \%$ & $20 \%$ & $80 \%$ \\
\hline Sentença 2 & $100 \%$ & - & - & $100 \%$ & - \\
\hline Sentença 3 & $80 \%$ & $20 \%$ & - & $80 \%$ & $20 \%$ \\
\hline Sentença 4 & $20 \%$ & $80 \%$ & - & $40 \%$ & $60 \%$ \\
\hline
\end{tabular}

Fonte: elaboração própria.

Ao observar os dados, nota-se que os integrantes do grupo que leu o Texto A tiveram $60 \%$ de acerto na resposta à primeira sentença, enquanto os participantes que leram o Texto B tiveram apenas $20 \%$ de acerto. Isso pode significar que a Figura C - relacionada a essa questão - pode ter auxiliado os leitores do Texto A, de alguma forma, na melhor compreensão do tópico tratado na sentença.

A segunda e a terceira sentença tiveram os mesmos resultados de acerto e erro em ambos os textos (100\% de acerto; $80 \%$ de acerto e $20 \%$ de erro, respectivamente). Isso pode sugerir que os gráficos $\mathrm{A}$ e $\mathrm{B}$, presentes no Texto $\mathrm{A}$ e relacionados a tais sentenças, só teriam a função de acompanhar a informação verbal, de sorte que esta pode ter sido mais preponderante para a compreensão das informações expostas nas sentenças.

A quarta sentença, por sua vez, foi a que teve um resultado inverso aos anteriores. Enquanto o grupo que leu o Texto A teve $20 \%$ de acerto, o grupo do Texto B teve $40 \%$. Embora a taxa de erro tenha sido grande em ambos os grupos (80\% e 60\%, respectivamente), a maior quantidade de erro entre o grupo que teve acesso ao Gráfico $\mathrm{C}$ - relacionado a essa sentença - pode apontar para uma possível dificuldade de os estudantes integrarem a informação verbal com a visual, exposta no gráfico, o que pode ter prejudicado a compreensão.

\section{CONSIDERAÇÕES FINAIS}

Neste trabalho, foram discutidos aspectos teóricos relacionados à atividade de leitura vista como um processo de produção de sentidos que se estabelece na relação autor-textoleitor e que ocorre sob a influência de diversos fatores - com foco em textos da área acadêmica. Dessa forma, foram abordadas questões relativas aos gêneros que circulam pelo ambiente acadêmico, o tipo de linguagem utilizada e, principalmente, os recursos multimodais presentes nesses textos.

O estudo teve como foco de análise recursos multimodais - mais especificamente ilustrativos - presentes em um artigo científico, procurando averiguar se esses recursos poderiam influenciar ou não o processo de leitura de um texto acadêmico.

Convém ressaltar o caráter exploratório do presente estudo. Tendo em vista a quantidade limitada de participantes, o trabalho apresenta resultados parciais (logo, não conclusivos) de uma pesquisa ainda em andamento e que será expandida em termos de referencial teórico e amostra.

Nessa perspectiva, os dados preliminares mostram que, em alguns momentos, o texto em que havia a presença de ilustrações foi mais bem compreendido pelos graduandos. Em outros momentos, a compreensão textual era a mesma para os dois textos, ou seja, os recursos multimodais não teriam uma influência direta no entendimento do conteúdo. 
Diante disso, os resultados sugerem que ilustrações - tais como figuras, tabelas e gráficos - podem gerar três tipos de efeito sobre o processo de leitura de um texto acadêmico: a) elas podem auxiliar na melhor compreensão do conteúdo e localização de informações específicas; b) podem apenas acompanhar a informação verbal, de sorte que esta seja preponderante para o entendimento de um assunto; e c) de certa forma, podem gerar algum tipo de dificuldade para o leitor integrar a informação verbal à visual, e, consequentemente, interpretar um dado.

\section{REFERÊNCIAS}

ARAÚJO, Júlio; PIMENTA, Alcilene Aguiar. Aspectos multimodais da escrita acadêmica em pôsteres de bolsistas da UFC: a construção de significados nesse gênero. E-Scrita: revista do Curso de Letras da UNIABEU, Nilópolis, v.5, n. 2, p. 106-122, maio/ago. 2014. Disponível em: https://bit.ly/2KCSVDj. Acesso em: 17 jun. 2019.

BEZERRA, Benedito. Gêneros digitais: apresentando livros na internet. Revista Signos, Lajeado, v. 43, n. 1, p. 45-61, 2010. Disponível em: https://tinyurl.com/y3c8ywr6. Acesso em: 17 jun. 2019.

ELIAS, Vanda Maria da Silva; SILVA, Sandro Luis da. Multimodalidade na escrita de artigos científicos: aspectos teórico-analíticos e contribuições para o ensino. Linha D’Água, São Paulo, v. 31, n. 1, p. 111-125, jan./abr. 2018. Disponível em: https://bit.ly/2W403hh. Acesso em: 17 jun. 2019.

FERREIRA, Lucas Pazoline da Silva. Ciberartigo: um modelo de produção (hiper)textual na comunicação científica online. 2017. Tese (Doutorado em Letras) - Universidade Federal de Pernambuco, Recife, 2017. Disponível em: https://bit.ly/358TAFS. Acesso em: 17 jun. 2019.

FLOREK, Cristiane Salete. Uma proposta didática para o ensino de leitura e de escrita de um gênero acadêmico multimodal. Veredas, Juiz de Fora, v. 20, n. 2, p. 239-256, 2016. Disponível em:

https://bit.ly/35eCUgu. Acesso em: 16 jun. 2019.

FREITAG, Raquel Meister Ko. Amostras sociolinguísticas: probabilísticas ou por conveniência? Revista de Estudos da Linguagem, v. 26, n. 2, p. 667-686, 2018. Disponível em: https://tinyurl.com/y4fdur4s. Acesso em: 22 fev. 2019.

IBGE. Normas de apresentação tabular. 3. ed. Rio de Janeiro: IBGE, 1993. Disponível em:

https://bit.ly/383JF5b. Acesso em: 24 jan. 2020.

KLEIMAN, Angela. Texto e leitor: aspectos cognitivos da leitura. 16. ed. Campinas: Pontes Editores, 2016. KOMESU, Fabiana. Letramentos acadêmicos e multimodalidade em contexto de EAD semipresencial. SCRIPTA, Belo Horizonte, v. 16, n. 30, p. 75-90, $1^{\circ}$ sem. 2012. Disponível em: https://tinyurl.com/y3nhh9tn. Acesso em: 16 jun. 2019.

LUPTON, Ellen. Pensar com tipos: guia para designers, escritores, editores e estudantes. Tradução André Stolarski. São Paulo: Cosac Naify, 2006.

LUZ, José Gilvan da. Estatística. Aracaju: Gutemberg, 2010.

MAYER, Richard E. Introduction to Multimedia Learning. In: MAYER, Richard E. The Cambridge Handbook of

Multimedia Learning. Cambridge: Cambridge University Press, 2005. p. 1-16. Disponível em:

https://pdfs.semanticscholar.org/fd09/96d9b55901cecacf4427fc1f6837d1868b7a.pdf. Acesso em: 02 jul.

2019.

MORAES, Andréa. Pôster acadêmico: um evento multimodal. Ao Pé da Letra, Pernambuco, v. 9, p. 1-9, 2007. Disponível em: https://tinyurl.com/y5rsq6lo. Acesso em: 17 jun. 2019.

MOTTA-ROTH, Désirée; HENDGES, Graciela Rabuske. Produção textual na universidade. São Paulo: Parábola Editorial, 2010.

PADILLA, Constanza. Desafios epistêmicos e argumentativos na escrita de pós-graduação: gêneros científico-acadêmicos e trajetórias de mestrandos e doutorandos. Trad. Raquel da Silva Ortega. EID\&A Revista Eletrônica de Estudos Integrados em Discurso e Argumentação, Ilhéus, n. 15, p. 270-295, jan./jun. 2018. Disponível em: https://bit.ly/37bvJGr. Acesso em: 12 nov. 2019.

SAMPAIO, R.F.; MANCINI, M.C. Estudos de revisão sistemática: um guia para síntese criteriosa da evidência científica. Revista Brasileira de Fisioterapia, São Carlos, v. 11, n. 1, p. 83-89, jan./fev. 2007. Disponível em: https://tinyurl.com/yy8s45oj. Acesso em: 28 maio 2019. 